\title{
TEORIA DO CAPITAL SOCIAL: UM ESTUDO NO CLUSTER MOVELEIRO \\ DE MARCO (CE)
}

\section{RESUMO}

O estudo objetivou descrever um arranjo produtivo local - APL, sob a ótica da teoria do capital social, em suas perspectivas cognitiva, relacional e estrutural, para evidenciar capacidades coletivas com o fim de atingir objetivos comuns e produzir riquezas. A pesquisa é qualitativa, descritiva, documental e de campo, na modalidade estudo de caso, tendo como unidade de análise o APL moveleiro de Marco (CE), pela sua longevidade e pelos seus resultados. A coleta de dados se fez em 2008, por meio de 25 entrevistas semiestruturadas com integrantes da cadeia de valor do cluster. A investigação permitiu caracterizar a dinâmica que sustenta o capital social do APL em suas forças, fraquezas e contradições, bem assim as interações subjacentes ao desenvolvimento de competências que favorecem resultados no plano individual, organizacional e comunitário. $\mathrm{O}$ estudo também evidenciou a importância da articulação, da mobilização e da organização do fator humano no desenvolvimento individual, institucional e econômico-social de um território.

Palavras-chaves: Competitividade. Desenvolvimento local. Arranjo produtivo local. Capital social. Cluster moveleiro.

\section{ABSTRACT}

This study aimed to describe a local productive arrangement from the viewpoint of social capital theory, adopting a cognitive, relational and structural outlook remarking collective action to achieve common goals with wealth production. The research is qualitative, descriptive, documental and field, in the case study method. It took place at furniture cluster of Marco, state of Ceará - Brazil, by its longevity and results reported. Data collecting was done through semistructured interviews with 25 subjects institutionally significant inside the APL value chain. The study allowed to describe the social capital dynamics which sustain the furniture cluster results in terms of strengths, weaknesses and contradictions, as well as the interactions underlying the development of skills that promote individual and collective outcomes. Thus, the study also highlights the role of coordination, mobilization and organization of the human factor for the individual, institutional and territory economic and social development.

Keywords: Competitiveness. Local development. Local productive arrangements. Social capita. Furniture cluster.

\author{
Serafim Firmo de Souza \\ Ferraz \\ Universidade Federal do Ceará \\ (UFC) \\ Doutor em Administração \\ ferraz@ufc.br \\ Raquel Lorena Gobb \\ Universidade Federal do Ceará \\ (UFC) \\ Mestre em Administração
}

\author{
Tereza Cristina Batista de \\ Lima \\ Universidade Federal do Ceará \\ (UFC) \\ Doutora em Educação \\ terezacristinalima@ufc.br
}

Recebido em 15/março/2011 Aprovado em 27/novembro/2011 


\section{INTRODUÇÃO}

A emergência da noção de capital social nas últimas décadas pôs em relevo o fator humano na já abundante produção acadêmica sobre desenvolvimento econômico e social. Grosso modo, o capital social pode ser compreendido como um bem coletivo que se constitui por meio da convergência de objetivos e da produção de resultados viabilizados por relações sociais que proporcionem o acesso de indivíduos e de organizações a recursos intelectuais, institucionais e materiais.

Como fundamento estratégico, o conceito de capital social vem dando suporte a análises e proposições que buscam combater o aumento da pobreza e das desigualdades, além de constituir fundamento dos estudos relativos à sustentabilidade. Apesar disso, a referida noção permanece, para muitos, vaga e imprecisa, e as suas repercussões no plano organizacional das estratégicas, dos processos e da gestão de pessoas são pouco exploradas.

Não se trata apenas da ressignificação da noção de capital humano, no bojo da habitual articulação com o capital físico e natural, presente na maior parte das teses atuais sobre a qualidade do ambiente social. Refere-se também à qualidade das interações sociais, sobretudo organizacionais e institucionais, em sua capacidade de romper impasses históricos, antropológicos, econômicos e sociais em benefício das populações de um território.

Essas interações sociais sugerem uma relação do capital social com as chamadas economias de aglomeração, favorecidas, segundo Amorim e Scipião (2007), pelas relações pessoais no bojo de estruturas sociais. Entre elas, constituem particular interesse os arranjos produtivos locais (APL) como substrato da mobilização e da especialização produtivas de atores individuais, organizacionais e institucionais em bases cooperativas e territoriais, para obtenção de benefícios recíprocos e do desenvolvimento local.

Assim, parece relevante explorar os vínculos entre a Teoria do Capital Social e a temática das configurações organizacionais alternativas, perpassadas pelas noções de competitividade, de resultados, de sustentabilidade, de governança e de competências tão caras à gestão organizacional contemporânea. A melhor compreensão dos elementos de análise intrinsecamente humanos do conceito de capital social pode aportar referenciais úteis para a Administração Estratégica e, em especial, para o conjunto de perspectivas relacionadas ao elemento humano nas organizações. Pode-se ainda acumular conhecimentos para projetos que visem promover desenvolvimentos econômico e social amplos.

Nesse contexto, este artigo objetiva descrever o arranjo produtivo local - APL moveleiro de Marco (CE) em suas perspectivas cognitiva, relacional e estrutural, para evidenciar a capacidade de grupos e de organizações no desenvolvimento de trabalhos conjuntos e no alcance de objetivos comuns, com produção de riquezas. Nesse sentido, os aspectos operacionais, processuais e organizacionais do APL são privilegiados como elementos de análise e de evidenciação do capital social constituído.

\section{REFERENCIAL TEÓRICO}

\subsection{Arranjos Produtivos Locais - APL}

As associações entre regiões e aglomerações geográficas de empresas são frequentes nos estudos sobre competitividade desde o século XIX. Conforme Santos et al. (2007), essa questão tem como marco referencial os estudos de Marshall sobre as concentrações ou os distritos industriais das cidades inglesas de Manchester e de Sheffield. Para Marshal (1890), a concentração de firmas seria induzida (e indutora) por externalidades positivas que propiciariam vantagens competitivas impossíveis de serem obtidas, caso atuassem de forma isolada.

De acordo com Keller (2008), o interesse internacional pelos distritos industriais ganhou densidade acadêmica e política a partir das décadas de 1980 e de 1990, na esteira do debate que se estabeleceu sobre especialização flexível e a experiência de desenvolvimento socioeconômico por meio de distritos industriais na chamada Terceira Itália (região da Emilia Romagna). Para Keller (2008), a expressão "Terceira Itália" provém de Arnaldo Bagnasco (1999), referindo-se à região que se colocava de forma 
inovadora entre o norte desenvolvido (Primeira Itália) e o sul atrasado (Segunda Itália), evidenciando formas de organização industrial não-fordistas, caracterizadas pela aglomeração de firmas de pequeno e médio portes, segundo padrões de relacionamento e de cooperação complexos que incluíam instâncias governamentais, no âmago de uma "comunidade local".

No Brasil, as experiências de aglomerações produtivas revelam ambivalências importantes, face ao modelo de desenvolvimento excludente patrocinado pelo Estado durante a maior parte do século passado. Com efeito, Costa e Costa (2005) explicam que cluster, no sentido de APL e de distrito industrial, são formas da organização produtiva de bases históricas, resultantes do entrelaçamento dos ambientes econômicos e culturais, permeadas por relações sociais específicas a cada território em que se desenvolvem, sugerindo a possibilidade de um semnúmero de configurações possíveis em torno de um tipo ideal de APL. Em muitos casos, os distritos industriais no Brasil se constituíram sem laços culturais ou sociais mais evidentes, buscando, em princípio, os ganhos de escala resultantes da aglomeração simples de firmas, com base na obtenção de benefícios fiscais.

Por outro lado, o SEBRAE (2004) registra a sobreposição de diferentes formas de "clusterização", ao repertoriar experiências brasileiras de desenvolvimento econômico local em diferentes etapas de desenvolvimento e graus de maturidade. Embora carentes de avaliações mais profundas, essas experiências caracterizavam-se, em maior ou menor grau, pela concentração de pequenas e médias empresas em bases comunitárias ou territoriais e por especializações setoriais - de profissões ou de produtos -, organizadas em redes de relacionamentos horizontais e verticais.

Lastres e Cassiolato (2005), em complemento, definem arranjos produtivos locais como aglomerações territoriais de agentes econômicos, políticos e sociais, com foco em um conjunto específico de atividades econômicas e com relações de interdependência, de articulação e de vínculos consistentes. Para Fernandes (2005), a atuação em APLs pode favorecer as organizações, sobretudo aquelas de pequeno porte, tanto na conciliação entre economia de escala e flexibilidade como na redução de custos e/ou no estímulo às ações empreendedoras e de inovação. Barros e Moreira (2005) acrescentam que as redes de empresas e de instituições também favorecem o desempenho organizacional pela via de interações interorganizacionais mais intensas, conjugando a potencialização de diferenciais competitivos recíprocos dos ganhos de escala, ou pela redução das restrições de tempo e de espaço.

Floriano, Souza e Corrêa (2007) salientam a capacidade dos APLs de ampliar competitividade, facilitando a modernização e a sustentabilidade de empreendimentos, além de estimular processos locais de desenvolvimento. No processo que favorece a constituição de comunidades mais sustentáveis, com maior capacidade de suprir demandas imediatas, o despertar de vocações locais e o desenvolvimento de capacidades específicas assume especial destaque, mediante a articulação e a convergência de ações de governo e a celebração de parcerias com atores sociais diversos, sobretudo empresários.

Finalmente, em conformidade com More, Valle e Villela (2007), o desenvolvimento de um APL pode ser influenciado por fatores endógenos e exógenos. Os fatores endógenos - a) padrões de cooperação; b) compartilhamento de crenças e de valores; c) disseminação de práticas competitivas; d) minimização de custos de transação; d) disseminação tecnológica e de inovações; e) compartilhamento de ferramentas da gestão; f) estruturas de governança; g) dinâmica de agregação de novos empreendedores e instituições locais) -, em sintonia com fatores exógenos (entre outros, políticas públicas de incentivo; benefícios decorrentes de dinâmicas do mercado; acesso a financiamentos), podem contribuir de forma significativa para o fortalecimento dos laços de cooperação e de participação em um APL.

\subsection{Capital Social}

O conceito de capital social possui significados que se ajustam às mais variadas orientações teóricas e metodológicas e é utilizado - como categoria analítica - por sociólogos, antropólogos, economistas, cientistas políticos e teóricos do desenvolvimento macroeconômico e social. O conceito foi incorporado, 
aliás, às propostas de governos em todos os níveis, como também a instituições internacionais como o Banco Mundial, a Organização para a Cooperação Econômica e o Desenvolvimento - OECD e o Programa das Nações Unidas para o Desenvolvimento - PNUD (BRITO, 2006).

Portes (2000) registra a primeira análise sistemática da noção de capital social formulada em 1985 por Pierre Bourdieu, definindo-o como “[...] o agregado de recursos efetivos ou potenciais ligados à posse de uma rede durável de relações mais ou menos institucionalizadas de conhecimento ou reconhecimento mútuo".

O sociólogo James Coleman $(1988 ; 1990)$ é outro precursor desse corpo teórico na sociologia norteamericana, que define o capital social a partir da sua função: “[...] não é uma entidade singular, mas uma variedade de diferentes entidades, com dois elementos em comum: todos consistem de algum aspecto de uma estrutura social e facilitam certas ações dos indivíduos que estão no âmbito da estrutura".

Portes (2000), Barros e Moreira (2005), além de Neves e Helal (2006), destacam a contribuição de Coleman ao analisar o referido conceito de modo mais completo, relacionando-o ao conjunto de recursos inerentes às relações familiares e à organização social de comunidades, já que esses fatores contribuiriam para o desenvolvimento cognitivo e social do indivíduo. Assim sendo, o desenvolvimento pode ter origens não intencionais e circunstanciais, aportado por capital social constituído, sem o qual determinados objetivos econômicos e sociais não seriam alcançados, ainda que mobilizando formas tradicionais de capital.

A contribuição do cientista político Robert Putnam (1993) trouxe maior notoriedade ao conceito, ao definir capital social como a capacidade de grupos e de organizações da sociedade civil de desenvolver trabalhos conjuntos no alcance de objetivos comuns, de modo a possibilitar maior eficiência na produção coletiva de riqueza. Em pesquisa realizada na Itália, Putnam (1993) concluiu que pessoas unidas em associações têm maior consciência política, confiança social, participação política e "competência cívica subjetiva". Para o referido autor (1993), quanto maior a participação em associações locais, maior a cultura cívica.

James Coleman $(1988 ; 1990)$ e Robert Putnam (1993), os principais expoentes do conceito de capital social, destacam, enfim, elementos da organização social - redes, normas e relações de confiança, entre outros - que facilitariam a coordenação e a cooperação em prol de benefícios coletivos, ao mesmo tempo em que defendem o efeito potencializador do capital social sobre os investimentos em capital físico e capital humano.

Em síntese mais recente, Grootaert et al. (2004) ressaltam que o paradigma do capital social é discutido na literatura acadêmica de duas maneiras. A primeira maneira busca vincular o capital social à natureza e à extensão do envolvimento de agentes em redes informais e organizações cívicas formais. Nessa perspectiva, os autores veem o capital social como atributo de uma comunidade ou sociedade, com destaque para as redes de relacionamento como elemento do capital social. A segunda maneira foca os recursos aos quais os indivíduos podem ter acesso por meio das interações sociais. No primeiro caso, o capital social pertence ao grupo e não ao indivíduo. Já no segundo, o capital social traz componentes individuais.

Entre os autores brasileiros, destacam-se Augusto de Franco (2001) e Cangussu (2003), que definem o capital social como "a capacidade de cooperar de uma sociedade, através de pessoas que se organizam em redes e regulam seus conflitos democraticamente". Em uma perspectiva funcional, Albagli e Maciel (2003) definem o capital social como um recurso existente nas relações sociais de determinadas comunidades, facilitador da ação coletiva orientada para propósitos comuns e que conduzem a benefícios econômicos, políticos e/ou sociais. Chévez (2001) e Barros Moreira (2005) ressaltam, por fim, os aspectos empresariais, ao lado dos sociais, como elementos potencializadores do capital social desenvolvido em bases comunitárias, além de registrar o efeito combinado de fatores como as reciprocidades negociadas entre agentes, mediados por redes sociais, regras de cooperação e mecanismos de governabilidade.

Registram-se críticas, por fim, sobre o predomínio de uma visão positivada do conceito de capital social, 
contra o que Carpin (2005) objeta não ter a noção de capital social, em si, conotação positiva ou negativa, já que os seus efeitos e impactos dependeriam dos objetivos que motivariam a sua constituição, em cada contexto verificado.

Em síntese e a partir das diferentes concepções reunidas, pode-se compreender o capital social como bem coletivo, constituído por meio de relações de confiança, de cooperação e de coordenação em um meio social e interorganizacional, no qual indivíduos e organizações obtêm acesso a vantagens e mobilizam recursos (intelectuais, tecnológicos, mercadológicos e/ou financeiros) para atingir objetivos comuns.

Dimensões e elementos de análise do capital social - O desenvolvimento do capital social é, portanto, determinado pelo contexto e pela linguagem comum desenvolvida pelos indivíduos, além da qualidade das dinâmicas interpessoais e das estruturas de relacionamentos. Assim, é possível apreender em Nahapiet e Ghoshal (1998) e em Uphoff (2000) as três dimensões analíticas (e seus elementos constitutivos) que sustentam este estudo: a) a dimensão cognitiva; b) a dimensão relacional; c) a dimensão estrutural.

a) A dimensão cognitiva - Conforme Grootaert e Van Bastelaer (2002) e Silva e Salanek Filho (2006), a dimensão cognitiva se refereàs normas, aos valores, à confiança, às atitudes e às crenças que predispõem indivíduos a ações coletivas, em prol do benefício mútuo. Ela representa os recursos estabelecidos pelo compartilhamento de significados entre sujeitos e membros de redes de interesses e objetivos. Para Nahapiet e Ghoshal (1998) as interpretações e os sistemas de significados incluem a linguagem, os códigos e as narrativas socialmente compartilhadas (NAHAPIET; GHOSHAL, 1998). Com fins analíticos, a dimensão cognitiva desdobra-se em três elementos: 1) valores; 2) atitudes; 3) identidade.

1 - Os valores humanos, segundo síntese formulada por Giraldi e Ikeda (2007), constituem crenças duradouras de que um modo de conduta ou estado final de existência é preferível a outro.
Nesse sentido, constituem metas desejáveis que variam em importância e servem para guiar a vida das pessoas.

2 - A atitude é "uma tendência de responder a alguma pessoa, objeto ou situação, de modo positivo ou negativo" (MORGAN, 1977, p. 260). Rodrigues (1986, p. 345) sintetiza os elementos que caracterizam as atitudes sociais afirmando serem as atitudes um complexo ou "uma organização duradoura de crenças e de cognições em geral, dotada de carga pró ou contra um objeto social definido, predispondo a uma ação coerente com as cognições e afetos relativos a este objeto".

3 - A identidade social refere-se à parte “[...] do autoconceito do indivíduo que deriva do conhecimento que ele tem de si como membro de um grupo social (ou grupos) junto com o valor e o significado emocional associado à participação nesse mesmo grupo" (TAJFEL, 1982, p. 24). É constituída com base na classificação que os indivíduos fazem de si mesmo e dos outros, na condição de uma organização ou de uma afiliação religiosa, de gênero, de idade ou de qualquer outra categoria (TAJFEL; TURNER, 1985).

b) A dimensão relacional - Tem seu foco no papel e na diversidade dos laços diretos de relacionamento entre os agentes e os seus respectivos conteúdos transacionados nessas interações, comoaamizade, atrocadeinformações, o respeito, a confiança, as normas, as sanções e as identificações recíprocas (NAHAPEIET; GHOSHAL, 1998). Tem como elementos principais a confiança e a cooperação. Segundo Lewis e Weigert (1985 apud BREI; ROSSI, 2007), confiar significa a ação no pressuposto de que ações futuras incertas de outros sejam assumidas como certa, dentro das circunstâncias compartilhadas. Nesse caso, estabelece-se uma expectativa de ação proveniente daquele agente no qual a confiança está sendo depositada. Conforme Balestro (2004), para a dimensão relacional, a confiança interpessoal contribui para a criação de conhecimento em contextos 
onde há grande incerteza e ambiguidade, pois é ela que mantém os agentes ligados por meio de expectativas e crenças comuns, e não pela clareza dos propósitos e certeza dos resultados da ação conjunta. A cooperação, por sua vez, é a ação de colaboração voluntária e consciente, normalmente ligada a um objetivo comum compartilhado entre os agentes que a executam. No contexto dos APLs, Lastres e Cassiolato (2005, p. 9) defendem a posição de que a cooperação pode acontecer por intermédio dos seguintes fatores: 1) intercâmbio sistemático de informações produtivas, tecnológicas e mercadológicas; 2) interação de vários tipos, envolvendo empresas e outras organizações, por meio de programas comuns de treinamento, realização de eventos e feiras, cursos e seminários, entre outras ocorrências; c) integração de competências, pela realização de projetos conjuntos, incluindo desde a melhoria de produtos e processos até pesquisa e desenvolvimento propriamente ditos entre empresas, e entre elas e outras organizações.

c) A dimensão estrutural - Para Grootaert e Van Bastelaer (2002) e Silva e Salanek Filho (2006), a dimensão estrutural inclui as relações sociais por meio das quais informações são difundidas, facilitando as ações coletivas e a tomada de decisões pelos agentes. Refere-se, portanto, ao padrão de conexões entre os agentes ou o grau de conectividade dentro da rede de relações. Neste trabalho, a dimensão estrutural é verificada por meio do estabelecimento de papéis, do "empoderamento" e dos mecanismos de governança. Em uma perspectiva social, o papel significa um conjunto de condutas requeridas e esperadas de dado sujeito pelos demais indivíduos com quem se relaciona, indicativas de como devem ser seu comportamento e atitudes em determinados momentos e situações (HONÓRIO; MATTOS, 2007). O empoderamento, por sua vez, implica na alteração das relações de poder em favor daqueles que contavam com pouco poder (BRONZO, 2006) Pode ocorrer nos níveis individual, organizacional e comunitário.
$\mathrm{O}$ individual diz respeito ao crescimento da capacidade dos indivíduos influírem na sua própria vida; o organizacional significa contribuir com as decisões da organização (empresarial) para melhorar seu desempenho; o comunitário capacita os "grupos sociais desfavorecidos para a articulação de seus interesses e participação comunitária, visando conquista plena dos direitos de cidadania, defesa de direitos e de influenciar ações do Estado" (PASE, 2007, p. 7). Por fim, a governança pode ser entendida e considerada sob o foco da corresponsabilização, que se apresenta associada diretamente à cooperação, à participação ativa, à forma de tomada de decisão coletiva, ao fluxo de comunicação (que produz o compartilhamento efetivo das informações) e conhecimentos, à correalização e ao desenvolvimento humano e social e de todos os participantes (FRANCO, 2004).

Com base nos elementos característicos do conceito de arranjo Produtivo Local é possível perceber que os APLs, na sua concepção ideal, são tão mais consistentes na medida em que desenvolvem dimensões e elementos de capital social, simultaneamente nos planos cognitivos, relacionais e estruturais.

\section{METODOLOGIA}

Esta pesquisa tem natureza qualitativa, classificando-se como descritiva. Quanto aos meios, trata-se de estudo documental e de campo, na modalidade estudo de caso, tomando como unidade de análise o APL moveleiro que tem como centro o município de Marco, Estado do Ceará. A escolha desse APL se deu por tipicidade, em vista da sua relevância econômica e territorial e pela maturidade da experiência.

Os dados operacionais, processuais e organizacionais do APL foram coletados entre fevereiro e abril de 2008, por meio de entrevistas semiestruturadas com 25 sujeitos de 24 organizações, escolhidos por representatividade na cadeia de valor do arranjo, conforme tabela abaixo. Citados dados foram confrontados com a pesquisa documental junto 
a instituições de apoio e observação direta, como a participação de pesquisador em duas reuniões em março de 2008: a primeira, da AMMA - Associação dos Moveleiros de Marco, e a segunda, do núcleo de governança, com representantes da AMMA, do SEBRAE, do SENAI e das indústrias moveleiras não associadas à AMMA, além de fornecedores e distribuidores que compõem a cadeia produtiva respectiva.

Tabela 1: Número de Organizações Visitadas e Sujeitos Entrevistados por Segmento

\begin{tabular}{c|c|c|c|c|c|c}
\hline & \multicolumn{5}{|c}{ Número de Organizações Visitadas e Sujeitos Entrevistados } \\
\hline Quantidade & Indústrias & $\begin{array}{c}\text { Produtores } \\
\text { informais }\end{array}$ & Fornecedores & Clientes & Instituições & Total \\
\hline Organizações & 11 & 05 & 02 & 02 & 04 & 24 \\
\hline Sujeitos & 11 & 05 & 02 & 02 & 05 & 25 \\
\hline
\end{tabular}

As entrevistas foram conduzidas por meio de quatro questionários com questões abertas - para instituições de apoio, indústrias de móveis, produtores informais, clientes e fornecedores, respectivamente. As entrevistas foram realizadas em sua maior parte em Marco, mas aconteceram também em Sobral e Fortaleza-CE).

Para preservar a confidencialidade das fontes, foram utilizadas as seguintes designações: a) Empreendedor Formal (para os dirigentes das indústrias formais); b) Empreendedor Informal (para os produtores informais); c) Fornecedor (para os comércios fornecedores de insumos); d) Cliente (para as lojas de móveis; e) Empregado de Instituição (para os representantes das Instituições).

\section{ANÁLISE DE DADOS}

\section{$4.1 O$ arranjo produtivo moveleiro de Marco (CE)}

O APL em estudo está localizado em território que tem como núcleo o município de Marco, localizado na região noroeste do Estado do Ceará, a $272 \mathrm{~km} \mathrm{da}$ capital Fortaleza. Fundado em 22 de novembro de 1951, o início da produção estruturada de móveis no município teve início em 1996. Naquele ano, a cidade de Marco contava com 18.711 habitantes (IPECE, 2006). A maioria da população economicamente ativa dependia das atividades agrícolas ou de empregos públicos, e as atividades industriais eram marginais. Historicamente, o município de Marco registrava um expressivo número de marcenarias, consequência da situação do município localizado na chamada "rota da madeira", passagem do transporte proveniente da região amazônica.

Configuração atual do APL - A cadeia de valor que constitui o APL moveleiro de Marco está representada na Figura 1, distribuindo-se em três blocos: cadeia de suprimentos, núcleo central e cadeia de distribuição, inseridos em um macro contexto social, econômico, cultural, legal e político, atinentes ao sertão cearense.

No núcleo central, encontram-se os principais atores do APL, representados pelas indústrias de móveis e pelos pequenos produtores informais. As indústrias associadas formam a Associação dos Moveleiros de Marco - AMMA, que, juntamente com as instituições de apoio, compõem o núcleo de governança do APL. Apesar de não fazer parte do núcleo de governança, também compõem o arranjo indústrias formais não associadas à AMMA, ao lado de pequenos produtores informais, além de bancos e instituições educacionais. A pesquisa de campo pôde identificar, à época, a existência de 20 (vinte) indústrias formalmente constituídas, das quais foram pesquisadas 11 indústrias, sendo 10 associadas à Associação dos Moveleiros de Marco - AMMA, afora 5 produtores informais (pequenas marcenarias).

O setor produtivo de móveis do APL de Marco é composto por indústrias especializadas em móveis residenciais. Os empresários negociam periodicamente a produção de produtos acabados para minorar a competição entre pares. São produzidos no arranjo estofados, salas de jantar, dormitórios e móveis para jardins, elaborados com madeira, fibras naturais, vidro, ferro e alumínio. Um diferencial dos móveis produzidos em Marco é a produção em madeira maciça, o que agrega qualidade ao produto, tornando-o mais competitivo no mercado nacional. Nos últimos anos, tem-se agregado novos materiais para compor o produto final, como é o caso do emprego de MDF (placa de fibra de madeira de média densidade), para permitir maior maleabilidade no uso, com redução do 
desperdício de materiais. Na elaboração de modelos e design, os empresários buscam "inspiração" para suas novas coleções em feiras e eventos do ramo por todo o Brasil e no exterior, bem como em revistas especializadas. Na criação dos novos produtos, utiliza-se "projetos híbridos", baseados em pequenas adaptações e ajustes sobre os modelos originais reproduzidos, adaptados ao padrão tecnológico e ao maquinário existente nas fábricas, por meio da engenharia reversa.

No APL é comum a prática da subcontratação. As empresas de maior porte realizam contratos informais de produção com os menores e pequenos produtores informais, por meio da produção de semiacabados, cabendo à empresa contratante a execução do trabalho final. Nesse contexto de sublocação, costuma-se ter elevado nível de exigência, primando pela qualidade do produto. Geralmente são feitos contratos informais por lote de fabricação dos produtos.
Em relação aos pequenos produtores informais, identificou-se a existência de, aproximadamente, 10 negócios informais (marcenarias), que empregam, em média, 03 (três) funcionários cada uma. Os produtores, em geral, são ex-funcionários de outros pequenos negócios de móveis e das indústrias mais antigas existentes em Marco. Fabricam móveis sob encomenda, reformam sofás, portas, entre outros itens menores, direcionando-se a maior parte da produção ao atendimento de encomendas de consumidores finais do próprio município. Os produtores informais têm como maiores concorrentes as próprias lojas de móveis do município, que facilitam o pagamento em até 10 (dez) parcelas, atrativo mercadológico que se situa fora do alcance dos primeiros.

Em relação ao mercado fornecedor, observou-se que a matéria-prima é oriunda de diversas regiões do País, provindo a madeira dos estados do Pará e da Bahia (sul). Itens como tecidos, tintas e espumas são

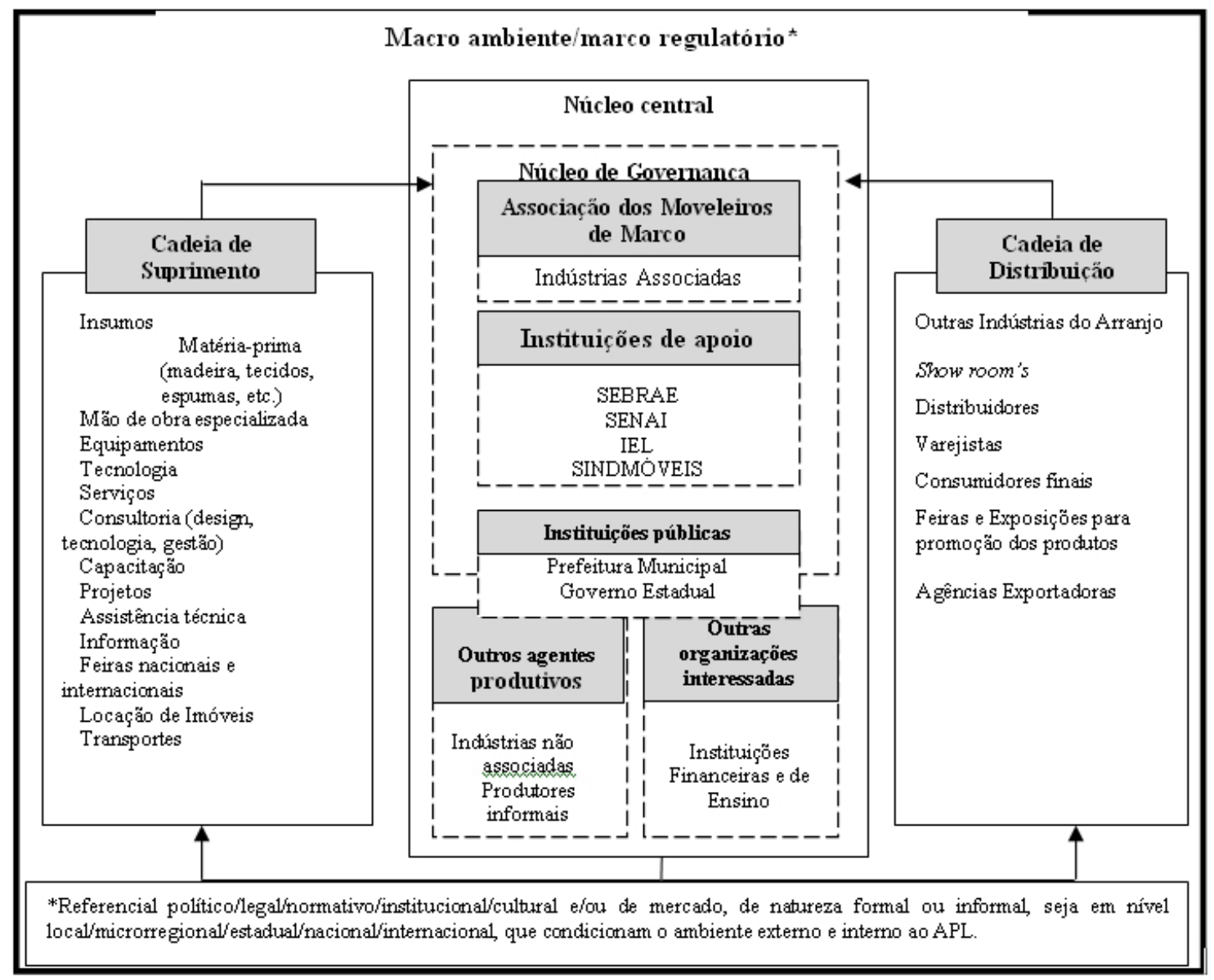

FIGURA 1 - Cadeia de Valor do APL de móveis de Marco 
provenientes das regiões Sul e Sudeste do País, adquiridos diretamente dos fornecedores. No que diz respeito aos fornecedores do próprio município, obtém-se uma variedade de insumos secundários para as indústrias e pequenas marcenarias, tais como madeira, tecidos, fios, tintas, grampos, compensado, espumas, entre outros. Os principais clientes são os pequenos produtores de móveis do município, atendendo, também, em menor escala, a municípios vizinhos

Quanto ao mercado consumidor, constatou-se que o destino dos móveis fabricados em Marco é bem diverso, com comercialização no próprio município e até no exterior. No mercado nacional, coloca-se a produção em praticamente todo o território nacional, inclusive com alguns pontos de vendas próprios. A predominância das vendas, entretanto, ocorre nas regiões Norte e Nordeste (70\%), seguido do Estado do Ceará (17\%) tomado de maneira isolada, ao lado de outras regiões do País (9\%). No mercado externo, comercializa-se com o México, Porto Rico, Estados Unidos, Portugal e Alemanha (4\%), entre outros países. No que tange às lojas de móveis localizadas no município, elas adquirem grande parte de seus produtos das indústrias de Marco. Segundo os lojistas, os móveis de Marco são procurados por consumidores de vários municípios da região que escolhem os móveis lá produzidos pela qualidade, durabilidade e variedade de modelos. Outra vantagem de comercializar os produtos fabricados em Marco é a redução dos impostos em relação aos móveis trazidos de outras regiões do País, o que permite a prática de preços mais acessíveis.

Desempenho do APL - No que diz respeito aos resultados econômicos e sociais advindos do desempenho do Arranjo, ficou evidenciada a geração de emprego e renda, bem como a melhor qualificação das pessoas inseridas no contexto do município e da região.

A cidade de Marco configurou-se como o principal município da região a ofertar vagas de trabalho na iniciativa privada. Conforme Lima (2007), houve evolução significativa na geração de emprego no segmento de móveis, visto que no ano de 1996, quando teve início a constituição do APL, eram ofertados cerca de 80 empregos diretos no município. Cerca de dez anos depois, ao final de 2007, apenas as 10 empresas aglutinadas na Associação dos Moveleiros de Marco - AMMA empregavam 903 empregos diretos. Esse número pode ser muito maior, já que deixa de incluir as 10 empresas não associadas à AMMA, nem um número ainda não disponível de empreendimentos informais e pelas unidades que estão a montante e a jusante da cadeia de valor. A organização do APL também favoreceu a geração de pequenos negócios que participam da cadeia produtiva de móveis, o que contribuiu para uma maior dinamicidade e autonomia do município e para o desenvolvimento local da região.

O desempenho do APL também pode ser verificado pela qualificação do pessoal. De fato, uma das principais dificuldades encontradas pelos empresários no início do desenvolvimento do arranjo foi, com unanimidade destacada, a falta de empregados qualificados. A maior parte dos empresários precisou trazer funcionários da cidade de Fortaleza e do sul do País para que eles ensinassem o ofício aos demais empregados das fábricas.

Hoje, após pouco mais de dez anos do início do desenvolvimento do Arranjo, essa dificuldade foi superada. A experiência adquirida ao trabalhar juntamente com profissionais experientes e qualificados, nas capacitações obtidas por meio das instituições parceiras, proporcionou a elevação do nível de qualificação das pessoas. A socialização de conhecimentos no arranjo elevou também a qualificação dos empresários e foi difundida, em grande parte, pelos profissionais trazidos de outras regiões do País, onde a produção moveleira é tradicional, como design. Conforme uma das Instituições, os empresários, hoje, já sabem "caminhar sozinhos", pois os consultores contratados têm apresentado resultados satisfatórios.

Nesse contexto, podem ser observados elementos facilitadores da constituição do capital social, como é o caso da autonomia em buscar competências inexistentes no local, como também da socialização dos conhecimentos obtidos e melhores práticas produtivas e de mercado, abrindo espaço para ações compartilhadas e articuladas entre os atores, resultando num ganho social para as empresas, para o grupo e 
para o município.

\subsection{Análise na perspectiva das dimensões do capital social}

Conforme visto, a análise de conteúdos se deu por meio da apreensão dos elementos que compõem as dimensões cognitiva, relacional e estrutural do capital social, interdependentes e mutuamente reforçadas.

\subsubsection{A dimensão cognitiva}

Nesse segmento, os valores, as atitudes e as identidades são abordados na condição de elementos cognitivos do capital social. Os valores são princípios ou padrões sociais aceitos ou mantidos por um indivíduo, grupo ou uma sociedade, constituindo-se em metas desejáveis que servem para guiar a vida das pessoas, bem como para motivá-las a perseguir determinado comportamento. No APL estudado, puderam ser verificados valores de confiança, de solidariedade, de qualidade, de inovação e de crescimento, conforme se pode apreender dos depoimentos dos sujeitos:

[...] As empresas são bem entrosadas umas com as outras, não tem esse negócio de rivalidade. [...] Aqui é assim, se eu precisar eu vou lá ela me empresta, se ela precisar eu empresto, depois paga na mesma mercadoria (EMPREENDEDOR FORMAL 4)

[...] em qualidade o Marco não perde em nada. $\mathrm{O}$ próprio consumidor eles procuram logo os móveis do Marco, porque eles têm essa qualidade, são móveis de madeira pura, tudo é de primeira qualidade, a matéria-prima é de qualidade. O próprio pessoal daqui já adquiriu essa confiança (CLIENTE 2).

Observa-se, pelos depoimentos selecionados, que os valores são incorporados por todos os representantes da cadeia de valor. Isso indica que há uma articulação, por parte dos mesmos, em torno de um objetivo comum. Nesse ponto, o capital social cognitivo dá suporte ao capital social estrutural pelo nível de organização que está se consolidando no APL.

No que diz respeito às atitudes, aquela manifestada com maior frequência foi a cooperação:

A gente sempre passa informações para outras empresas, alguma novidade, troca informações e conhecimentos, então se a gente vê um modo mais fácil de produzir, ou se conhece uma pessoa de fora, um profissional que saiba fazer uma produção mais fácil, alguma inovação ou coisa diferente, a gente passa pra associação pra ver se ele tem interesse nessa nova ideia (EMPREENDEDOR FORMAL 2).

Observa-se a capacidade dos atores de compartilharem recursos, bem como esforços, informações e conhecimentos. Essa colaboração é voluntária e está relacionada à existência de um objetivo comum entre os atores que a executam, tornando viável a atitude de cooperação.

Em se tratando da identidade social, foi percebido o sentimento de inclusão dos atores ao território e à produção de móveis, demonstrando a identificação deles com o seu meio, como se pode constatar por meio dos depoimentos a seguir.

Você não sabe a emoção, imagina entrar numa feira de móveis e encontrar um pavilhão só com os móveis de Marco, é muito lindo, você ver só o seu povo ali, é lindo demais (EMPREGADO DE INSTITUIÇÃO 1).

Agora é que nós estamos começando. Seremos talvez os melhores do Brasil porque hoje somos os melhores do Nordeste. Temos os melhores móveis do Nordeste [...] [indústrias] (FORNECEDOR 1).

Observa-se um apego ao local, um sentimento de pertencimento dos atores ao arranjo, verdadeira paixão pelo espaço que ocupam. No estudo do capital social, esse sentimento é importante por vincular o indivíduo ao seu meio, fortalecendo a identidade local.

\subsubsection{A Dimensão relacional}

A dimensão relacional do capital social relaciona-se com o nível das relações entre atores sociais do ambiente em estudo, tendo como elementos de caracterização a confiança e a cooperação entre pares. A existência do atributo "confiança" entre os membros do grupo pôde ser observada no nível de amizade e proximidade dos relacionamentos (pessoais e profissionais), que favorecem a interação e a colaboração dos atores 
(produtivos, institucionais e organizacionais), bem como da reciprocidade nas ações deles. Um exemplo disso é a troca de informações e o empréstimo de matéria-prima e equipamentos entre os empresários, destacados nos depoimentos a seguir:

As empresas são bem entrosadas umas com as outras, não tem esse negócio de rivalidade. As mesmas coisas que eu fabrico a [...] fabrica, mas aqui é assim, se eu precisar eu vou lá ela me empresta, se ela precisar eu empresto, depois paga na mesma mercadoria (EMPREENDEDOR FORMAL 4).

O que eu acho mais importante [...] é essa amizade que a gente tem aqui, essa união [...]. A gente tem essa interatividade um com o outro, tanto de passar um preço melhor, como também de emprestar material (EMPREENDEDOR INFORMAL 5).

Constatou-se que os laços de amizade entre os empresários foram criados e fortalecidos pela aproximação familiar existente entre a maior parte das empresas do Arranjo. Os empresários, no entanto, afirmam que esse não é o principal motivo que justifica os fortes laços de união do grupo, pois existem empresas sem qualquer grau de grau de parentesco com as demais e, ainda assim, existe relação de amizade e interação.

No âmbito comunitário, pôde-se constatar que existe um vínculo de relações estáveis que combinam aceitação do risco comum e sentimento de afetividade e valores associativos, em destaque nos depoimentos abaixo:

Pode até vir uma outra pessoa abrir uma fábrica que a gente dá o mesmo apoio a esta pessoa, porque o que a gente quer é aumentar o APL, aumentar nossa região, produzindo mais (EMPREENDEDOR FORMAL 2).

Se mais e mais empresas ficam famosas por seus produtos, por sua qualidade, fortalece a marca do lugar e melhora a reputação de todos os produtores (EMPREENDEDOR FORMAL 7).

Com relação à cooperação, ela foi verificada por meio da troca sistemática de informações produtivas, tecnológicas e mercadológicas entre os atores do APL, bem como da constante interação envolvendo empresas e outras organizações, por meio de programas comuns de treinamento, realização de eventos, feiras e visitas técnicas, favorecendo a condução dos negócios. Ao mesmo tempo em que demonstra uma forma de cooperação entre os empresários, a troca de informações também reflete o grau de confiança entre eles. Assim, a troca de informações dentro do grupo foi ressaltada em todas as entrevistas realizadas, especialmente entre os empreendedores formais.

No tocante às ações cooperativas mencionadas com maior frequência pelos empresários como de fundamental relevância para as empresas destaca-se a logística, tanto de suprimento como de distribuição, já que o volume coletivo pode propiciar melhores condições de compra, a exemplo de melhores preços e prazos de materiais, bem como de frete. Trata-se de uma ação ainda não implementada, mas que está ao alcance de todas as empresas, podendo ser viabilizada pela AMMA, uma vez que grande parte da matéria-prima é comum à maioria das indústrias. Para que isso ocorra, será necessário maior amadurecimento da Associação, das demais instituições e, sobretudo, dos empresários, na crença dos efeitos positivos proporcionados pelas ações realizadas de forma conjunta.

Um ponto que pode ser promovido por meio da cooperação é a capacidade de inovação local, mediante projetos associativos de pesquisa e desenvolvimento de novos produtos e processos, difusão e absorção de novas tecnologias, de capacitação e desenvolvimento em design, de qualidade e certificação dos produtos. Podem ser estimuladas, ainda, as parcerias com centros tecnológicos e instituições de ensino e pesquisa para produzir e difundir conhecimentos para o APL. Esse ponto é particularmente importante para o APL, pois os esforços na pesquisa e no desenvolvimento de produtos e de design ainda são insipientes, requerendo o direcionamento de ações para esse fim.

\subsubsection{A Dimensão estrutural}

Essa dinâmica refere-se às conexões existentes na rede de relacionamentos entre atores: quem se relaciona com quem e como fazem. Assim sendo, os 
aspectos estruturais do capital social verificam-se no sistema de papéis e no empowerment dos atores sociais, ao lado dos mecanismos de governança instituídos no Arranjo. O Quadro 1 apresenta os diversos atores no território do APL de móveis, agrupados em três perspectivas: econômica, institucional e política.

Quanto à organização produtiva, observou-se que o APL de móveis de Marco foi estruturado, em grande parte, com recursos dos próprios empresários. Em contrapartida, o desenvolvimento do Arranjo somente foi possível por meio dos papéis desempenhados por diversos parceiros que atuaram em maior ou menor escala no Arranjo, entre os quais pode-se mencionar o SEBRAE, o SENAI, a AMMA, o Sindicato das Indústrias do Mobiliário no Estado do Ceará SINDMÓVEIS, o Instituto Euvaldo Lodi - IEL e os Governos Estadual e Municipal de Marco.

QUADRO 1 - Organizações atuantes no território do APL de móveis de Marco

\begin{tabular}{|c|c|c|c|}
\hline \multicolumn{3}{|c|}{ Organizações atuantes no território do Arranjo produtivo de móveis de Marco } \\
\hline \multicolumn{2}{|c|}{ Perspectiva Econômica } & $\begin{array}{c}\text { Perspectiva } \\
\text { Institucional }\end{array}$ & $\begin{array}{c}\text { Perspectiva } \\
\text { Política }\end{array}$ \\
\hline Atores Produtivos & Atores Comerciais & & \\
\hline Indústria 1 & & AMMA & Prefeitura Municipal \\
Indústria 2 & Fornecedores & SEBRAE & Governo Estadual \\
Indústria 20 & Distribuidores & SENAI \\
Produtor Informal 1 & IEL & \\
Produtor Informal 2 & Clientes & SINDMÓVEIS \\
$\ldots$ & & Ensituições de Crédito e & \\
Produtor Informal 10 & & & \\
\hline
\end{tabular}

A organização das empresas pertencentes ao Arranjo se fez em torno de uma empresa-âncora (Ruah Indústria). Até meados de 2005, essa empresa concentrava a parcela mais significativa das transações comerciais das indústrias instaladas em Marco, como responsável pelas compras de matérias-primas e pelas vendas de grande parte dos produtos lá fabricados. É unânime a avaliação acerca da centralidade do papel aglutinador e da liderança do dirigente da Ruah Indústria na constituição ou startup do cluster de móveis de Marco. A ampliação do APL, entretanto, não pode prescindir da institucionalização de uma instância coletiva capaz de canalizar os interesses de cada unidade produtiva, preservando sentido coletivo ao lado da autonomia e da independência das partes. Nesse sentido, a criação da AMMA, constituída inicialmente com o propósito de adquirir terrenos para a construção de fábricas, passou a representar, a partir de 2006, a principal instância de aglutinação e de mediação de interesses de empresários e de outros membros relevantes da cadeia de valor.

No tocante à participação e ao trabalho coletivo na busca do desenvolvimento das partes e do conjunto, ganhou destaque, a partir de então, o planejamento estratégico como atividade realizada de forma compartilhada entre os atores, momento em que se negociam papéis, regras e ações conjuntas, sob a ênfase dos elementos que se abrigam nas dimensões relacional e estrutural do capital social. No Arranjo, o planejamento é realizado por meio do projeto Gestão Estratégica Orientada para Resultados - GEOR (SEBRAE), e visa identificar fatores chaves de demandas relevantes (sociais e empresariais), condições de mercado, potencialidades, dificuldades, pontos de estrangulamento ou desafios, de acordo com a singularidade das micro, pequenas e médias empresas. Mais recentemente, a partir de 2008, foi constituído em bases coletivas o Plano de Desenvolvimento do APL de móveis de Marco, trabalho em parceria com o Núcleo Estadual de Apoio aos Arranjos Produtivos Locais, o IEL e a Secretaria das Cidades do Governo do Estado do Ceará. O Plano seguiu as premissas do Manual Operacional do Plano de Desenvolvimento do Ministério do Desenvolvimento, Indústria e Comércio Exterior, apresentando análise do ambiente externo e interno, com organização sistemática das ações realizadas nos anos de 2006 e 2007, ao lado de uma projeção das ações a serem implementadas no quadriênio 2008-2011. Ressalta-se que a atuação do SEBRAE por intermédio do referido programa é limitada às indústrias associadas, não incluindo as não associadas e os negócios informais (marcenarias), que se situam, via de regra, às margens das ações realizadas no APL.

Em relação ao empowerment ou empoderamento, 
segunda dimensão da análise, no que diz respeito às ações creditícias, as empresas associadas têm à disposição, desde o ano de 2008, o Cartão BNDES, que consiste na contratação de crédito preaprovado e rotativo para aquisição de matéria-prima, máquinas e equipamentos. Percebe-se que há a necessidade da inserção de instituições parceiras com maior potencial de contribuição de recursos para o Arranjo, tais como o governo do estado e a Prefeitura de Marco, atores políticos que compõem a dimensão estrutural. No que diz respeito ao governo estadual, os empresários reclamam por uma parceria mais estratégica, que atente para a vocação local do município, objetivando a valorização e a ampliação das ações que estão em pauta de desenvolvimento. $\mathrm{Na}$ opinião desses entrevistados, é vasto o campo de melhorias que podem ser empreendidas por tais instituições, sendo que as principais queixas incorrem na carga tributária, por parte do governo estadual, e na ausência de linhas de crédito mais baratas para os microempresários.

$\mathrm{Na}$ esfera municipal não foi verificado nenhum plano de ação mantido por uma secretaria específica. Percebe-se que a prefeitura atua de forma indireta no desenvolvimento do Polo. Conforme a Instituição, ela contribui com a isenção dos tributos municipais (emissão de alvarás e IPTU) para os pequenos produtores e indústrias, com o intuito de ajudar o segmento produtivo a investir mais em sua produção. Também colabora com a Associação emprestando, eventualmente, o Auditório no qual são realizadas as reuniões com os empresários e representantes das instituições.

As indústrias do Arranjo também são associadas ao SINDMÓVEIS, que tem o papel de representar a indústria moveleira na sociedade cearense, atuando na prospecção de mercado interno e na promoção das feiras TOP MÓVEL e FEMAC, em que a participação é viabilizada, parcialmente, por intermédio do SEBRAE; no entanto, ações específicas para o Arranjo estudado não foram destacadas. Além das dificuldades relatadas anteriormente relacionadas aos atores políticos, a maior parte dos empresários reclama da contribuição financeira das instituições parceiras, justificando que ela é insuficiente comparando-se às necessidades deles.
Com base no exposto, há uma percepção amplamente compartilhada de que a AMMA precisará ampliar a sua atuação institucional e política, unindo atores do cluster mantidos à margem pela informalidade, como também uma aglutinação espacial para além do contorno geográfico do município, pois o APL moveleiro já possui conotação territorial que abrange os municípios vizinhos. Nesse sentido, parece requer-se da AMMA uma capacidade de articulação política, com estruturas de governança melhor desenvolvidas, face às exigências advindas do crescimento do cluster. A AMMA, a instância maior de governança instituída, cumpre papel relevante pela função de aglutinar interesses e de facilitar as relações sociais e mercadológicas. A necessidade do desenvolvimento institucional e organizacional da AMMA em particular e do APL em geral se faz sentir até em reforço dos elementos que se abrigam nas dimensões cognitivas e relacionais do capital social. É também nos planos cognitivos e relacionais, com suporte da dimensão estrutural, que a superação de relacionamentos políticos atávicos e de parentesco constatados em Marco possam ser definitivamente substituídos, sem traumas, por uma comunidade baseada em normas, valores e de relações sociais baseadas em conceito ainda mais amplo de confiança e de cooperação, com ganhos de competitividade.

\section{CONSIDERAÇÕES FINAIS}

Este estudo objetivou analisar um Arranjo Produtivo Local - APL sob a ótica das perspectivas cognitiva, relacional e estrutural da teoria do capital social, a partir da análise de elementos operacionais, processuais e organizacionais caracterizadores do cluster moveleiro de Marco, Estado do Ceará. Nesse sentido, a pesquisa tem como premissa que o conceito de capital social constitui elemento qualificador da noção de cluster e de arranjos produtivos locais pelas características comunitárias, de participação, de mobilização e de articulação que definem ambos os conceitos.

A origem do Arranjo Produtivo Local foi favorecida por características econômicas e empreendedoras não endógenas com base em ações 
articuladas entre personagens locais e poder público municipal e estadual. O Arranjo institucional em torno do núcleo produtivo e a cadeia de valor constituiu-se ao longo do tempo, fomentando a configuração de um núcleo de governança autônomo que se encontra em consolidação e que já permite visualizar seus próprios limites diante do contexto de crescimento e complexidade.

O estudo pode registrar geração de trabalho, emprego e renda, seguidos da melhoria da qualidade de vida da população local, como principais resultados econômicos obtidos a partir da organização do APL. Verificou, ainda, a elevação do nível de qualificação de pessoal, obtida por meio de uma aprendizagem coletiva e do desenvolvimento organizacional, e favorecida pela convergência de interesses e pela troca de conhecimentos, de experiências e de informações entre os atores.

A análise da dimensão cognitiva do capital social identificou a presença de "valores" de confiança, de solidariedade, de qualidade, de inovação e de crescimento. Identificou-se ainda, a "atitude" de cooperação como a mais recorrente entre os atores associados. Pelo estudo do elemento "identidade" foi constatado o sentimento de inclusão dos atores ao território e à produção de móveis, demonstrando a identificação deles com o seu meio.

Da análise da dimensão relacional verificou-se a existência de fortes laços de cooperação e confiança entre os atores produtivos associados e as instituições de apoio. No entanto, entre os atores produtivos informais e os não associados não foram observadas relações de confiança e cooperação à luz da teoria estudada. Entre os atores produtivos associados e os atores produtivos informais verificou-se apenas relações verticais de cooperação. Foi constatada, também, a ausência de algumas formas de cooperação, típicas de aglomerações produtivas amadurecidas com alto nível de articulação entre os atores individuais e institucionais. Essas ações dizem respeito à pequena participação do poder público local, à ausência de políticas de inclusão de produtores informais de móveis e as indústrias não associadas, e, ainda, a insatisfação dos associados com a insuficiência de recursos destinados pelas instituições de apoio presentes no Arranjo.

$\mathrm{Na}$ dimensão estrutural, foram observados os avanços institucionais obtidos pela Associação dos Moveleiros, recentemente constituída, em substituição à empresa-âncora que teve papel fundador do cluster. Ainda de presença marcante, dadas as relações de parentesco que ainda predominam entre os associados, a governança assumida pela AMMA como instância de mobilização, de articulação política e econômica, de negociação e articulação parece sugerir o desenvolvimento de estruturas mais ajustadas às necessidades de desenvolvimento do cluster, em bases mais sustentáveis. Constatou-se, também, que há espaço para ampliação do empoderamento de uma maior diversidade de atores locais, sobretudo daqueles não associados e dos produtores informais, não contemplados diretamente com os incentivos das instituições existentes.

Os avanços estruturais são sugeridos, igualmente, pela configuração da cadeia de suprimentos. Historicamente dependente do suprimento de madeira proveniente do Estado do Pará, paulatinamente os produtores locais souberam encontrar novas fontes de matéria-prima e capacitar-se para a elaboração de produtos com novos materiais - aço, sintéticos, entre outros -, tornando-se menos vulneráveis às restrições ambientais resultantes do desmatamento da região amazônica. A análise ambiental, portanto, conduziu à aprendizagem. Um ponto fraco que ainda persiste, entretanto, refere-se a questões de design. Os produtores de Marco ainda não desenvolveram competências nessa importante função competitiva. Desde o início, os produtores projetam produtos com base em cópias de peças expostas em estabelecimentos e feiras ou de "engenharia reversa".

Em que pese alguns descolamentos em relação aos fundamentos da teoria do capital social que ainda persistem - notadamente a base de parentesco das relações sociais e de produção; o desafio da leitura mercadológica e do design fundamentado em clonagem que sustenta o posicionamento estratégico baseado em custos e preços mais baixos; a proeminência da liderança e da empresa-âncora fundadores, entre outros - é inegável que o APL de Marco se apresenta como gerador de capital social, distinguindo-o positivamente 
em relação às regiões circunvizinhas, por meio do aglutinamento, da aprendizagem e do paulatino desenvolvimento de competências institucionais, organizacionais e coletivas, que incluem a gestão. Com base neste estudo, a constituição do capital social, baseado no equilíbrio e no desenvolvimento recíproco de um conjunto amplo de elementos cognitivos, relacionais e organizacionais, parece favorecer o desenvolvimento de um território sustentado em uma cultura de cooperação e de organização em bases competitivas, cuja mensuração quantitativa permanece carente de avaliação, a exemplo do que sugerem Camilo, Carvalho e Xavier (2009) e Sgarbi (2009) em estudos exploratórios sobre o fenômeno dos arranjos produtivos locais e das aglomerações em geral.

\section{REFERÊNCIAS}

ALBAGLI, Sarita; MACIEL, Maria Lúcia. Capital social e 'empreendedorismo' local. Proposição de política para a promoção de sistemas produtivos locais de micro, pequenas e médias empresas. 2003. Disponível em: $<$ www.ie.ufrj.br/ redesist $>$. Acesso em 01/02/2007.

AMORIM, Mônica Alves; SCIPIÃO, Tatiana Teófilo. $O$ território e a organização da pequena produção. Fascículo 3. Universidade Aberta do Nordeste, 2007.

BALESTRO, Moisés Villamil. Redes de Inovação e capital social: apontamentos conceituais. In: Encontro Nacional de Pós-Graduação em Administração - ENANPAD, 2004. Anais eletrônicos... Curitiba: Anpad, 2004.

BARROS, Francisco Sávio de Oliveira; MOREIRA, Maria Vilma Coelho. O Capital Social nas Aglomerações Produtivas de Micro e Pequenas Empresas: Estudo de um Arranjo Produtivo Turístico. In: Encontro Nacional de PósGraduação em Administração - ENANPAD, 2005. Anais eletrônicos... Brasília: Anpad, 2005.

BREI, Vinícius. A.; ROSSI, Carlos A. Vargas. Confiança, valor percebido e lealdade em trocas relacionais de serviço: um estudo com usuários de internet banking no Brasil. Revista de Administração Contemporânea, v. 9, n. 2, abr./ jun., p. 145-168, 2005.

BRITO, Adriana Mariano de. A manifestação do capital social e da competência técnica em arranjo produtivo local (apl). Estudo de caso: apl de equipamentos e instrumentos médico odontológicos de campo mourão. Dissertação de Mestrado. Programa de Pós- graduação em Tecnologia. Universidade Tecnológica Federal do Paraná. Curitiba, 2006.

BRONZO, Carla. Políticas locais de inclusão social, autonomia e empoderamento: reflexões exploratórias. In Encontro Nacional de Pós-Graduação em Administração ENANPAD, 2006. Anais eletrônicos... Salvador: Anpad, 2006.

CAMILO, Sílvio P. O.; CARVALHO, Carlos E.; XAVIER, Vlamir G. Agrupamento dos setores da economia nacional segundo o seu desempenho: estudo utilizando análises fatorial e de clusters. Contextus Revista Contemporânea de Economia e Gestão. Vol.7 - No 2 - jul/dez/2009. (0720). Disponível em: http://www.contextus.ufc.br/index. php/contextus/issue/view/18

CANGUSSU, Tatiana Jordão Maia. A manifestação do capital social em Projetos de desenvolvimento de pequenos municípios: um estudo de caso na cidade de Lunardelli-PR. Dissertação de Mestrado. Programa de Pósgraduação em Administração - PPA. Universidade Estadual de Londrina e Universidade Estadual de Maringá. Maringá, 2003.

CARPIN, Thais Regina Pavês. Políticas públicas e ampliação de capital social em comunidades segregadas: o programa Santo André mais igual. Dissertação de Mestrado. Programa de Pós-graduação em Ciência Política. Universidade Federal de São Paulo. São Paulo, 2005.

COLEMAN, James. Foundations of Social Theory. Cambridge, MA: The Belknap Press of Harvard University, 1990.

COLEMAN, James. Social Capital in the creation of human capital. American Journal of Sociology, v. 94, p. S95S120, 1988.

COSTA, Aquiles Barcelos da.; COSTA, Beatriz Morem da. Cooperação e capital social em arranjos produtivos locais. (2005). Trabalho apresentado no XXXIII Encontro Nacional de Economia, 6 a 9 de dezembro de 2005. Disponível em: $<$ http://www.anpec.org.br/encontro $2005 /$ artigos/A05A113.pdf $>$ Acesso em: 2/3/2007.

CREMONESE, Dejalma. Insolidarismo e Cordialidade: uma análise das mazelas políticas do Brasil. In: BAQUERO, Marcello; CREMONESE, Dejalma. (Orgs.). Capital Social: teoria e prática. Editora Unijui. Ijui, RS, 2006.

FERNANDES, Bernardo Mançano. Movimentos socioterritoriais e movimentos socioespaciais: contribuição teórica para uma leitura geográfica dos movimentos. Revista NERA, ano 8, n. 6 - janeiro/junho de 2005.

FLORIANO, Fernanda; SOUZA, Antônia Egídia de; CORRÊA, Hamilton Luiz. Impacto ambiental: estudo no arranjo produtivo local de calçados de São João Batista/SC. ENANPAD, Rio de Janeiro, 2007.

FRANCO, Augusto de. Capital social. Brasília: Instituto de Política Millennium, 2001.

. O Lugar mais Desenvolvido do Mundo: investindo 
no capital social para promover o desenvolvimento comunitário. Agência de Educação para o Desenvolvimento - AED, 2004.

GIRALDI, Janaina de M. Engracia; IKEDA, Ana Akemi. Valores Pessoais como Base para Segmentação Estratégica: um Estudo com Executivos Brasileiros. In: Encontro Nacional de Pós-Graduação em Administração - ENANPAD, 2007. Anais eletrônicos... Rio de Janeiro: Anpad, 2007.

GROOTAERT, Christian; NARAYAN, Deepa; JONES, Verônica N.; WOOLCOCK, Michael. Measuring Social Capital. An Integrated Questionnaire. The World Bank, n. 18, 2004.

HONÓRIO, José Bezera; MATTOS, Pedro Lincoln C. Leão de. Papéis Organizacionais: O que a Pragmática da Linguagem nos Leva a Pensar. In: Encontro Nacional de Pós-Graduação em Administração - ENANPAD, 2007. Anais eletrônicos... Rio de Janeiro: Anpad, 2007.

IPECE (2006). Anuário estatístico do Ceará. Disponível em: http://www.ipece.ce.gov.br/publicacoes/anuario/ anuario2006/ Acessado em 14/03/2008.

KELLER, Paulo Fernandes. (2008). Cluster, distritos industriais e cooperação interfirmas: uma revisão da literatura. Disponível em:

http://www.iceg.pucminas.br/espaco/revista/16Clusters $\% 20$ $\% 20$ distritos $\% 20$ industriais $\% 20$ e $\% 20$ coopera $\% \mathrm{C} 3 \% \mathrm{~A} 7 \% \mathrm{C} 3 \% \mathrm{~A} 30 \% 20 \mathrm{in}$ terfir..pdf. Acessado em 26/04/2009.

LASTRES, Helena M. M.; CASSIOLATO, José E. Glossário de Arranjos e Sistemas Produtivos e Inovativos Locais. Rio de Janeiro, 2005. Disponível em http://redesist.ie.ufrj. br/glossario.php Acesso em 01/02/2007.

MARSAHL, Alfred. Principles of Economics. Amherst, New York, $1^{\text {a }}$ edição, 1997.

MORE, Jesus Domech; VALLE, Mírian Rosa do; VILLELA, Lamounier Erthal. Modelo Fuzzy para Avaliação de Influência de Fatores Endógenos e Exógenos no Desenvolvimento de um APL - Aplicação no Caso de Cabo Frio-RJ. ENANPAD, Rio de Janeiro, 2007.

MORGAN, Clifford T. Introdução à Psicologia. São Paulo: McGraw-Hill do Brasil, 1977.

NAHAPIET, Janine; GHOSHAL, Sumantra. Social Capital, intellectual capital and the organizacional advantage. The Academy of Management Review, vol. 23, n. 2. Apr 1998. p. $242-266$.

NEVES, Jorge Alexandre Barbosa; HELAL, Diogo Henrique. Superando a Pobreza: o papel do capital social na Região Metropolitana de Belo Horizonte. In: Encontro Nacional de Pós-Graduação em Administração - ENANPAD, 2006. Anais eletrônicos... Salvador: Anpad, 2006.
PASE, Hemerson Luiz. Capital social e empoderamento. Trabalho apresentado no II Seminário Nacional de Movimentos Sociais, participação e cidadania. Florianópolis, 25 a 27 de abril de 2007. Disponível em:

$<\mathrm{htt} / /$ :www.sociologia.ufsc.br/npms/hemerson_luiz_pase. pdf> Acesso em: 21/05/2007.

PORTES, Alejandro. Capital social: origens e aplicações na sociologia contemporânea. Sociologia, Problemas e Práticas, n. 33, 2000, p.133-158.

SGARBI, Victor S. O arranjo produtivo local como potencializador da vantagem competitiva: a visão dos participantes do APL de turismo região lagoas em alagoas. Contextus Revista Contemporânea de Economia e Gestão. Vol. 7 - No 2 - jul/dez/2009. (21-28). Disponível $\mathrm{em}$ : http://www.contextus.ufc.br/index.php/contextus/issue/ view/18

SANTOS, Leonardo Lemos da Silveira; ALVES, Ricardo César; SÜNDERMANN, Jorge; ALMEIDA, Kenneth Nunes Tavares de. "Artifícios" Para a Construção de uma Estratégia Coletiva: o Desenvolvimento de um APL na Indústria Pirotécnica no Centro-Oeste Mineiro. In: Encontro Nacional de Pós-Graduação em Administração - ENANPAD, 2007. Anais eletrônicos... Rio de Janeiro: Anpad, 2007.

SEBRAE. Metodologia de desenvolvimento de arranjos produtivos locais. Projeto Promos-SEBRAE/BIS: versão 2.0. Brasília, SEBRAE, 2004, 287 p. Disponível em: www. biblioteca.sebrae.com.br/bte/bte.nsf/C41C2DC053DE975 E03256F350063AF4C/\$File/NT000A0DA2.pdf. Acessado em 21/05/2007

SEBRAE. Termos de referência para atuação do sistema SEBRAE em arranjos produtivos locais. Brasília, 2003. Disponível em:

www.df.sebrae.com.br/.../pdf/apls/Atuação $\% 20$ do $\% 20$ Sistema\%20SEBRAE\%20em\%20APL's\%20-\%20 Principal.pdf. Acessado em 21/05/2007.

SILVA, Christian Luiz da; LOURENÇO, Marcus Santos; SALANEK FILHO, Pedro. Capital Social e Cooperativismo no Processo de Desenvolvimento Sustentável Local: Teorias e Aplicações ao Caso da Cooperativa Bom Jesus - Lapa/PR. In: Encontro Nacional de Pós-Graduação em Administração - ENANPAD, 2006. Anais eletrônicos... Salvador: Anpad, 2006.

TAJFEL, Henri. Social psychology of intergroup relations. Ann.Rev. Psychol, England, v. 33, 1982.

; TURNER, J. C. The social identity theory of intergroup behavior. In: S. Worchel e W.G. Austin . Psychology of Intergroup Relations, Chicago, NelsonHall, 1985.

UPHOFF, Normam. Understanding social capital: Learning from the analysis and experience of participation. In: Social Capital: a multifaceted perspective. In: DASGUPTA, 
Teoria do Capital Social: um estudo no cluster moveleiro de marco (CE)

Partha; SERAGELDIN, Ismail (Org). The World Bank, Washington, 2000.

YIN, Robert. K. Estudo de caso. 2. ed., Porto Alegre: Bookman, 2001.+ 